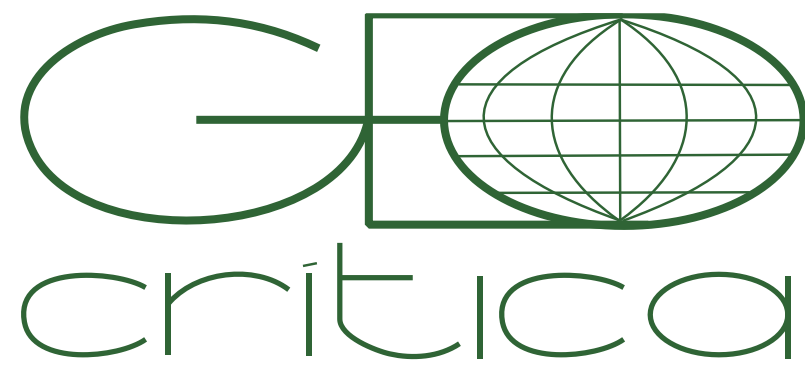

\section{Scripta Nova}

Revista Electrónica de Geografía y Ciencias Sociales

Universitat de Barcelona

ISSN: $1138-9788$

Vol. 25, Núm. 1 (2021), p. 141-167

\title{
LA INSTITUCIONALIZACIÓN DE “CONVENIOS URBANÍSTICOS" EN EL MARCO DEL PROCESO DE NEOLIBERALIZACIÓN DE LA GESTIÓN URBANA LOCAL
}

\author{
Natalí Peresini \\ CONICET- Consejo Nacional de Investigaciones Científicas y Técnicas CEVE \\ natperesini@gmail.com
}

Recibido: 4 septiembre 2020; Devuelto para correcciones: 9 diciembre 2020; Aceptado: 9 febrero 2021

\begin{abstract}
La institucionalización de "convenios urbanísticos" en el marco del proceso de neoliberalización de la gestión urbana local (Resumen)

Recientemente, tanto en Argentina como en otros países de la región, creció el uso de instrumentos de gestión urbana que habilitan operaciones inmobiliarias excepcionales con el fin de recuperar parte del plusvalor del suelo urbano generado a partir de ellas. Un mecanismo que pone de relieve la necesidad de financiamiento en los gobiernos locales. Este artículo presenta parte de los resultados obtenidos de una investigación que aborda el proceso de institucionalización de "Convenios Urbanísticos". En el caso de la ciudad de Córdoba (Argentina), en el período 2008-2019, los resultados muestran que la institucionalización de este mecanismo legitimó la mercantilización de la potestad regulatoria, la financiarización de desarrollos y empresas inmobiliarias en base al salto de renta y la concentración de los agentes que intervienen en la producción de suelo urbano.
\end{abstract}

Palabras claves: Neoliberalismo realmente existente, reestructuración regulatoria, gobierno local, financiarización urbana, convenios urbanísticos.

\section{The institutionalization of "convenios urbanísticos" throughout the neoliberalization} process in local urban management (Abstract)

In Argentina and other countries in the region, the use of urban management instruments has grown. Especially those used to allow exceptional real estate operations and recover part of the surplus value generated. A mechanism that highlights the need for financing in local governments. This article presents part of the results obtained from research on the institutionalization of the "Convenios Urbanísticos". In the case of Córdoba city, Argentina, between 2008 and 2019, the institutionalization of this mechanism shows that legitimized the commodification of regulatory power, the financialization the real estate developments and companies through the urban rent increase, and the concentration of agents in the production of urban land.

Key words: Actually existing neoliberalism, regulatory transformations, local government, financialization of the city, urban development agreements. 
En las últimas décadas el espacio urbano se convirtió en una pieza clave en y para el desarrollo de estrategias de acumulación y financiarización de capital (Harvey 2007a). Las ciudades son un objeto y escala privilegiada para el orden político-económico vigente. Sumado a ello, en Latinoamérica y fundamentalmente desde 1990, se presentó un escenario marcado por la globalización y apertura de mercados comerciales y financieros que estimuló a los gobiernos locales a asumir un nuevo rol y con ello, cambios en sus competencias y responsabilidades (De Mattos 2007; Pradilla Cobos 1997; Manzanal 1995). La adopción de un enfoque gerencial en la gestión urbana local sirvió de base para incentivar la competitividad interurbana y la eficiencia como variables estratégicas. Ambas, pensadas como recursos para la captura "creativa e inteligente" de capitales privados, fuente de ingresos para los gobiernos locales (Delgadillo 2014). En este proceso adquieren protagonismo tanto la orientación que asumen las políticas públicas como las decisiones de gestión urbana que acompañan y sostienen estos fenómenos.

En Argentina, parte de este proceso se materializa a partir de una serie de reformas macroeconómicas y regulatorias llevadas a cabo desde los años noventa ante la necesidad de adecuar la gestión gubernamental hacia un modelo políticoeconómico globalizado y competitivo (Manzanal 1995). Para ello, se tomaron una serie de medidas de clara orientación neoliberal: apertura de la economía a los mercados internacionales, privatización de los servicios y empresas públicas, facilitación de flujos financieros internacionales, desregulación y desmantelamiento de marcos regulatorios específicos para algunas actividades productivas. Así también, políticas descentralizadoras que dejaron a cargo de niveles sub nacionales los servicios de salud y educación (Centrángolo y Gatto 2002; Coremberg 2006). Estas medidas impactaron incluso en la reforma constitucional de 1994 que, entre otros aspectos, estableció la autonomía municipal en el orden institucional, político, administrativo, económico y financiero, determinada bajo el artículo $\mathrm{N}^{\circ} 123$. En la práctica, este proceso determinó la descentralización de responsabilidades, apoyados en el principio de subsidiaridad, sin la necesaria trasferencia de recursos y funcionó, además, como aval al modelo de competitividad para que cada municipio lograra generar y aumentar sus propios recursos económicos-financieros.

En este marco y en la última década se registró también una intensa campaña de circulación, difusión e incluso oferta formativa para los cuadros técnicos estatales, desde instituciones educativas y agencias de financiamiento internacional (tales como Lincoln Institute o el BID, entre otras), con el fin de exhibir casos y experiencias exitosas en torno a mecanismos e instrumentos financieros utilizados por gobiernos locales; gran parte de ellos vinculados a la recuperación de plusvalor a partir de operaciones inmobiliarias (Cuenya y González 2017; Barenboim 2015; Terraza et al. 2015). La paulatina pero constante incorporación de estos mecanismos e instrumentos en numerosos municipios de la región con el fin de expandir sus fuentes de financiamiento, acompaña en gran medida el nuevo rol de la gestión urbana municipal. Una gestión que, de acuerdo con el modelo de gobernanza urbana, debe 
fomentar y atraer capital inmobiliario para disminuir su dependencia de recursos ligada al centralismo estatal y desplazarse a una búsqueda de recursos empresariales.

Ahora bien, en gran parte de la literatura especializada, la financiarización del sector inmobiliario se analiza como parte de un fenómeno dependiente de las dinámicas del capital y, a menudo, es caracterizada a partir de los actores que intervienen, sus estrategias y los efectos socio-espaciales que provocan. Sin embargo, los mecanismos y resultados financieros resultantes de la mercantilización y neoliberalización de la gestión urbana, un proceso imprescindible ya que asegura las condiciones para su reproducción, aparecen escasamente en los análisis y en las discusiones teóricas. En relación con ello, tanto en Argentina como en los países de la región y sobre todo en la última década, tuvieron lugar una serie de mecanismos técnico-institucionales que legitimaron formas novedosas de vinculación públicoprivada. Fundamentalmente, aquellas orientadas a fomentar las inversiones urbanoinmobiliarias, en tanto que sirvan a impulsar, facilitar y sostener la circulación del capital. Nos referimos a aquellos instrumentos orientados a la recuperación de plusvalor, constituidos como estrategias para el financiamiento y obtención de ingresos tanto para los municipios que los normalizan e implementan como para los empresarios inmobiliarios que se ven favorecidos. Si bien las nomenclaturas y definiciones específicas de los instrumentos y mecanismos varían de acuerdo a los marcos legales de cada país (contribuciones por valorización y derechos de edificabilidad en Brasil, participación en plusvalías en Colombia, retorno de las valorizaciones en Uruguay o Convenios Urbanísticos en Argentina), podemos advertir la rápida apropiación y difusión que han logrado. En algunos casos, como el de los Certificados de Potencial Adicional de Construcción (CEPAC) utilizados para el financiamiento de obras públicas y como incentivo a Operaciones Urbanas Consorciadas en São Paulo, fueron emitidos por el municipio y comercializados en el mercado financiero como bonos (Smolka 2014; Sandroni 2011; Maricato y Ferreira 2002); un paso adelante en las estrategias y modalidades de financiarización de los gobiernos locales.

La investigación ${ }^{1}$ que aquí se expone, indaga este fenómeno mediante el estudio de caso, siguiendo las perspectivas conceptuales y analíticas de los estudios urbanos críticos. Se aborda el proceso de institucionalización de Convenios Urbanísticos (CU) en la ciudad de Córdoba, Argentina, en el período 2008-2019 con el fin de conocer las condiciones y estrategias normativas, institucionales y financieras desplegadas en su normalización e implementación. El caso de estudio muestra que los CU, si bien fueron habilitados como mecanismo jurídico-administrativo y económico-financiero para favorecer el desarrollo de la ciudad y promover la inversión privada, su institucionalización legitimó dos procesos diferentes. Por un lado, la mercantilización de la potestad regulatoria y por el otro, la financiarización de empresas desarrollistas a partir de la captura de valor por el salto de renta del suelo -de rural a urbano- como un

1 Proyecto de investigación doctoral (2016-2021) -datos de proyecto- financiado por el Consejo Nacional de Investigaciones Científicas y Técnicas-CONICET. 
mecanismo fundamental y aún vigente para el complejo urbano-inmobiliario en Argentina.

A los fines de este artículo, se organiza la información en cuatro partes. La primera intenta poner en diálogo las nociones teóricas y conceptos que problematizan los cambios recientes en la gestión urbana local asociados a los procesos económicosfinancieros del "desarrollo urbano". La segunda presenta las decisiones metodológicas que se han tomado para avanzar en la investigación y seguido a ello, en la tercera sección los principales resultados obtenidos del análisis empírico. Finalmente, se presentan algunas reflexiones a partir del estudio de caso en torno a estos instrumentos $\mathrm{y}$, con ello, de las estrategias de financiamiento apoyadas en la captura del salto de renta urbana.

\section{El proceso de neoliberalización en la gestión urbana local y la gobernanza urbana empresarialista realmente existente}

Desde hace décadas, la vinculación entre las condiciones político-económicas, los paradigmas de desarrollo que intentan reproducir y los modelos de gestión urbana que los avalan y materializan son problematizados desde los estudios urbanos. Emerge como interrogante hasta qué punto la producción económica influye en las modificaciones del marco institucional-normativo y si, finalmente este último no solamente se encuentra subordinado sino al servicio del mercado inmobiliario. Desde 1970 hasta la actualidad, los estudios urbanos críticos coinciden en señalar que las políticas urbanas han sido modeladas en función de los intereses de ciertos agentes: los promotores inmobiliarios y las empresas constructoras, generando nuevos patrones a través de sus operaciones en el espacio urbano (De Mattos 2011; Topalov 1978; Logan y Molotch 2015[1976]). En relación a ello, Logan y Molotch exponen la tesis de la ciudad como máquina de crecimiento en la cual se afirma que las políticas urbanas, estrategias y mecanismos de actuación están orientadas a promover la mayor expansión posible, de acuerdo con los intereses de las coaliciones de poder y destinadas a "engrasar" la máquina, funcionando como un "corporativismo urbano". Más recientemente Harvey ( 1989; 2007b) postula el concepto de "empresarialismo urbano" y traslada la noción de "governance" desde las ciencias políticas para comprender el impacto de las transformaciones en la gestión urbana bajo el orden neoliberal. De manera muy general, la noción de gobernanza urbana empresarialista intenta describir y definir las características de la gestión gubernamental en la actualidad, bajo condiciones de debilidad institucional, falta de recursos propios o necesidad de financiamiento, buscando salvar estas faltas a través de la incorporación de actores y recursos del sector privado. En este sentido, la orientación empresarialista se manifiesta a través de tres principios básicos: (1) la promoción de alianzas entre sector público y sector privado (como una asociación simétrica de intereses que combina el capital privado con capacidades gubernamentales, a los fines de atraer fuentes de financiamiento, nuevas inversiones directas o fuentes de empleo); (2) la lógica empresarial que orienta las decisiones (caracterizada por la necesidad de generar 
oportunidades de negocios con un alto grado de especulación inmobiliaria); y (3), una marcada orientación a la economía política del lugar (en términos de alcance y escala, esta vez orientados hacia programas y planes urbanos sectoriales) (López Morales, Gasic, y Meza 2012). Pese a las lecturas que acusan un Estado disminuido, se aprecia un rol activo del mismo que hace de la promoción de la actividad económica un objetivo ineludible para las políticas urbanas, ya que el crecimiento de las ciudades tanto en términos cualitativos como cuantitativos, dependen de las condiciones que ofrezcan las administraciones locales para la revalorización y circulación del capital.

Otros autores señalan también que las ciudades se han convertido en los últimos treinta años en un campo de incubación, experimentación y despliegue de políticas estatales y restructuraciones institucionales ${ }^{2}$, convirtiéndose en un campo estratégico para concretar la aplicación de la agenda neoliberal, lo que han definido como "urbanismo neoliberal" (Theodore, Peck, y Brenner 2009; Peck, Theodore, y Brenner 2009). Peck y Tickell (2014), invierten la relación y proponen pensar en una "espacialización del neoliberalismo" 3 considerando que se ha utilizado a la ciudad y su gestión como terreno de prueba de estrategias en el que cada componente de la ciudad se torna objeto de negocio y especulación. Ambas definiciones apuntan a reconocer que este proceso convirtió a las ciudades en "laboratorios institucionales", con el indispensable acompañamiento gubernamental, ya que se han ejecutado numerosas adaptaciones legales y regulatorias para facilitar la experimentación de políticas neoliberales. En relación a ello, Brenner et. al. (2011) proponen la noción de restructuración regulatoria para definir el desmantelamiento de formas de gestión estatal que son ajenas a los principios neoliberales a la vez que se promueve un patrón de cambios institucionales, regulatorios y socio-espaciales que sirvan a la expansión, financiarización y concentración de la economía. Los autores proponen este concepto para analizar los procesos de transformación urbana ligados al neoliberalismo, rescatando los matices existentes de acuerdo al contexto de aplicación, determinados por los diferentes marcos institucionales, prácticas regulatorias y luchas políticas aproximándonos al concepto de "neoliberalismo realmente existente"(Brenner y Theodore 2002).

En concreto, se señala que se logró legitimar la coalición gubernamental con los agentes de mercado en el plano formal, en los objetivos institucionales y en los marcos regulatorios, ya que los procesos de mercantilización están siempre mediados por las instituciones estatales. En este sentido, Fainstein sostiene que la financiarización es intrínseca a la neoliberalización y que las asociaciones público-privadas son la forma institucional del desarrollo especulativo (Fainstein y Novy 2019 en Aalbers 2020). Por ello, discutir los mecanismos concretos de la gobernanza urbana empresarialista en la

2 Traducción propia de "We conclude by considering the ways in which cities have become strategically essential arenas for neoliberalizing forms of policy experimentation and institutional restructuring. This, we argue, signals an important mutation in the nature of neoliberalization processes themselves since the early 1990s" (Peck, Theodore, y Brenner 2009, p. 54).

3 Traducción propia de "Neoliberalizing Space". 
gestión urbana resulta un punto clave para pensar los alcances e implicancias de estos mecanismos y ampliar al debate en torno a la financiarización urbana que trae consigo la neoliberalización.

En otro sentido, Janoschka (2014) menciona que se ha prestado mucho interés en las consecuencias territoriales del neoliberalismo urbano, aunque no así en conocer cuáles y cómo son los procesos que provocan esas reconfiguraciones urbanas. El autor se pregunta qué nuevas prácticas trae la agenda neoliberal a las ciudades latinoamericanas y destaca la creación e institucionalización de nuevas reglas, regulaciones, programas y micropolíticas que han establecido una legislación urbanística dispuesta a los intereses del sector inmobiliario en favor del desarrollo económico urbano. Como expresa Araujo (2010), ya no se trata de analizar el antagonismo entre regulación o desregulación, sino de entender las formas y modalidades combinadas, híbridas, que han tenido lugar bajo el orden neoliberal.

Bajo estas condiciones, advertimos que los municipios han desarrollado una serie de operaciones técnico-normativas e institucionales bajo la consigna de la recuperación de plusvalía. En muchos casos, con el fin de posibilitar arreglos específicos y excepcionales en el cumplimiento del marco normativo a determinadas operaciones inmobiliarias, con beneficiosos económicos tanto para el mismo gobierno local como para los inversores privados. Se trata de habilitar y legitimar cambios en la regulación urbana sobre, fundamentalmente, el uso del suelo e índices constructivos con el fin de favorecer y potenciar los rendimientos económicos. De este modo, el suelo urbano y el marco normativo que lo regula se convierte en un recurso y una mercancía negociable que sirve como fuente de financiamiento para los municipios inmersos en una lógica de supervivencia competitiva para sostener el crecimiento económico, ante la necesidad de diversificar las fuentes de ingresos y ganar autonomía respecto de los niveles superiores.

\section{Marco metodológico}

Para abordar el proceso de institucionalización de Convenios Urbanísticos y conocer las condiciones normativas, institucionales y financieras desplegadas en su normalización e implementación, se optó por una estrategia metodológica de base cualitativa, a través de un enfoque exploratorio-descriptivo a través de un estudio de caso (Sautu 2005). Dado que el proceso de neoliberalización se entiende como multiescalar y pluridimensional, se tomaron una serie de decisiones para que resulte factible su análisis. En primer lugar, se optó por enfocar la indagación en la gestión urbana local, dado el rol preponderante de las ciudades en el proceso de neoliberalización, sin dejar de lado la comprensión y caracterización del proceso en el contexto regional y global. Sumado a ello, el marco legal-institucional en Argentina define los municipios como autónomos y exclusivamente responsables de regular y elaborar las normas de uso y ocupación del suelo en su jurisdicción (Levenzon 2012), lo que limita la unidad de análisis al área donde tienen competencia. 
En cuanto al problema planteado, se propone abordarlo mediante tres dimensiones: (1) la normalización del instrumento, intentando identificar qué tipo de regulación se propone, modalidad planteada, a qué actores incorpora o excluye de la operación; (2) su implementación, para distinguir qué actores participaron, plazos de aplicación, intensidad, ubicación de las operaciones; y (3), su legitimización, al identificar actores que avalaron o se opusieron, reclamos y conflictos en torno a su uso, cumplimiento de los objetivos propuestos, revisiones y modificaciones.

Como dijimos y a diferencia de otros países, Argentina mantiene la condición de autonomía municipal en la regulación de los procesos de creación, fraccionamiento y uso del suelo dentro de los límites de cada ciudad. Por ello se han normalizado e implementado instrumentos de recuperación de plusvalor de acuerdo con las posibilidades e intereses coyunturales de cada municipio. La exploración de casos devuelve una tendencia casi sincrónica entre 2008 y 2012 en la cual se registró la institucionalización de CU en municipios de diferentes orientaciones ideológicas y políticas. El caso que se decide abordar pertenece al universo de CU en Argentina, que hasta la fecha se encuentran en las ciudades de Rosario (Ord. $N^{\circ} 8973 / 2012$ ), Tandil (Ord. $\mathrm{N}^{\circ}$ 12679/2011) y Córdoba (Ord. $\mathrm{N}^{\circ} 12077 / 2012$ ) con reglamentación específica para ello. La exploración también arroja que en las ciudades de Santa Fe (Ord. $\mathrm{N}^{\circ}$ 11748/2012), Rafaela (Ord. $\mathrm{N}^{\circ}$ 4170/2009) y La Plata (Ord. $\mathrm{N}^{\circ}$ 10703/2010) se ha legalizado este mecanismo bajo normas de ordenamiento urbano que los incluyen como instrumentos. Se decide tomar como caso de estudio el proceso que involucra la institucionalización de CU en la ciudad de Córdoba, entre 2008-2019, de acuerdo a la utilización de esta figura en la gestión local. La decisión se apoya en su jerarquía, escala urbana, influencia en el sistema nacional de ciudades, cantidad de CU celebrados y el acceso a la información e informantes claves dada la cercanía con el caso. El estudio delimitó el área de análisis al ejido municipal, es decir dentro de los límites políticosadministrativos de la ciudad en el cual el gobierno local tiene potestad jurídica.

Para la construcción y análisis de datos se utilizó la estrategia de triangulación (Benavides y Gómez-Restrepo 2005) que involucró el análisis de documentos oficiales (normativa y planes urbanos del gobierno local), no oficiales (notas periodísticas) y bibliografía relacionada; la recuperación ${ }^{4}$ y realización de entrevistas semiestructuradas a informantes claves mediante la técnica bola de nieve; y, el cruce con datos estadísticos de fuentes oficiales e instituciones académicas ${ }^{5}$. En total se realizaron treinta entrevistas. Las primeras veinte, permitieron conocer la posición en relación con los C.U. de actores del ámbito privado, tales como empresarios inmobiliarios y representantes de grandes empresas constructoras de la ciudad, de actores del gobierno local (funcionarios y representantes del área ejecutiva en relación con las políticas urbanas) y actores comunitarios de organizaciones civiles. Las restantes diez,

\footnotetext{
4 Entrevistas ejecutadas y sistematizadas en equipo en un proyecto de investigación anterior.

5 Para los datos estadísticos se utilizó la información censal del Instituto Nacional de Estadísticas y Censos -INDEC-
} 
permitieron conocer la visión de personal público técnico especializado y de referentes académicos.

\section{La institucionalización de Convenios Urbanísticos en la ciudad de Córdoba, Argentina}

La ciudad de Córdoba es la segunda ciudad en población de Argentina, con 1.329.604 habitantes según el último censo (INDEC 2010) y, conforme datos oficiales, cuenta con $576 \mathrm{~km}^{2}-57.600$ ha- lo que determina una densidad de $2.308 \mathrm{hab} / \mathrm{km}^{2}$. Ha tenido un constante crecimiento de población desde su fundación, aunque en la actualidad se observa una tendencia decreciente (gráfico 1) afectada principalmente por la movilización de habitantes hacia ciudades aledañas que integran su área conurbada.

Gráfico 1: Evolución del crecimiento de la población de la ciudad de Córdoba. 1810- 2010. Absolutos.

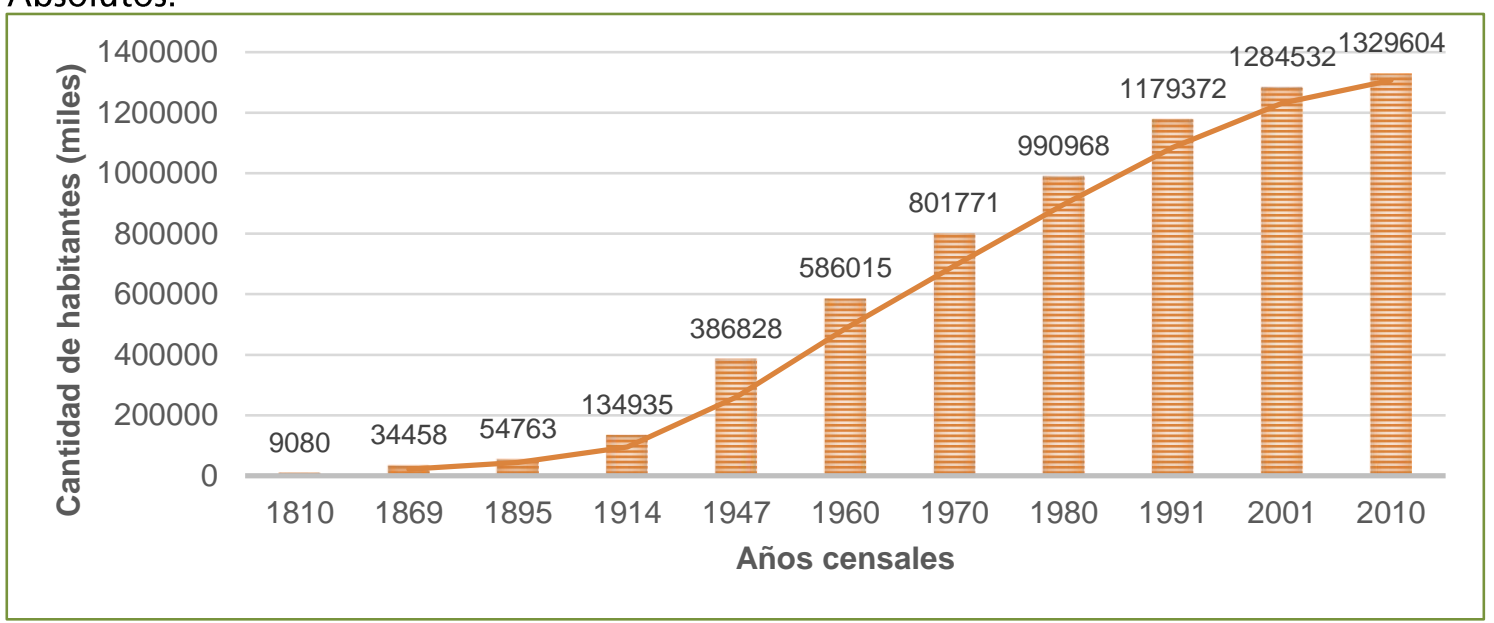

Fuente: Elaboración propia en base a datos del INDEC. Censos nacionales de población, hogares y viviendas

Por su carácter de capital provincial, Córdoba concentra actividades de administración gubernamental, salud, educación provincial y nacional (universidades), actividad productiva industrial y de servicios, además de un centro comercial consolidado desde hace más de cincuenta años. A su vez, es la cabecera del aglomerado Gran Córdoba, en una ubicación central que lo convierte en un nodo articulador para el corredor comercial bioceánico y norte. En la actualidad, cuenta con un centro histórico y barrios peri centrales consolidados desde su fundación, una mancha urbana circundante de diferentes características socioeconómicas según localización y una periferia dispersa (imagen 1), con presencia de urbanizaciones aisladas tanto de alto nivel socioeconómico (barrios cerrados y countries de elite) como por su opuesto, concentrados en "barrios ciudades" ejecutados como plan de vivienda social. 
Imagen 1: Tipo de ocupación en la ciudad de Córdoba a 2019.

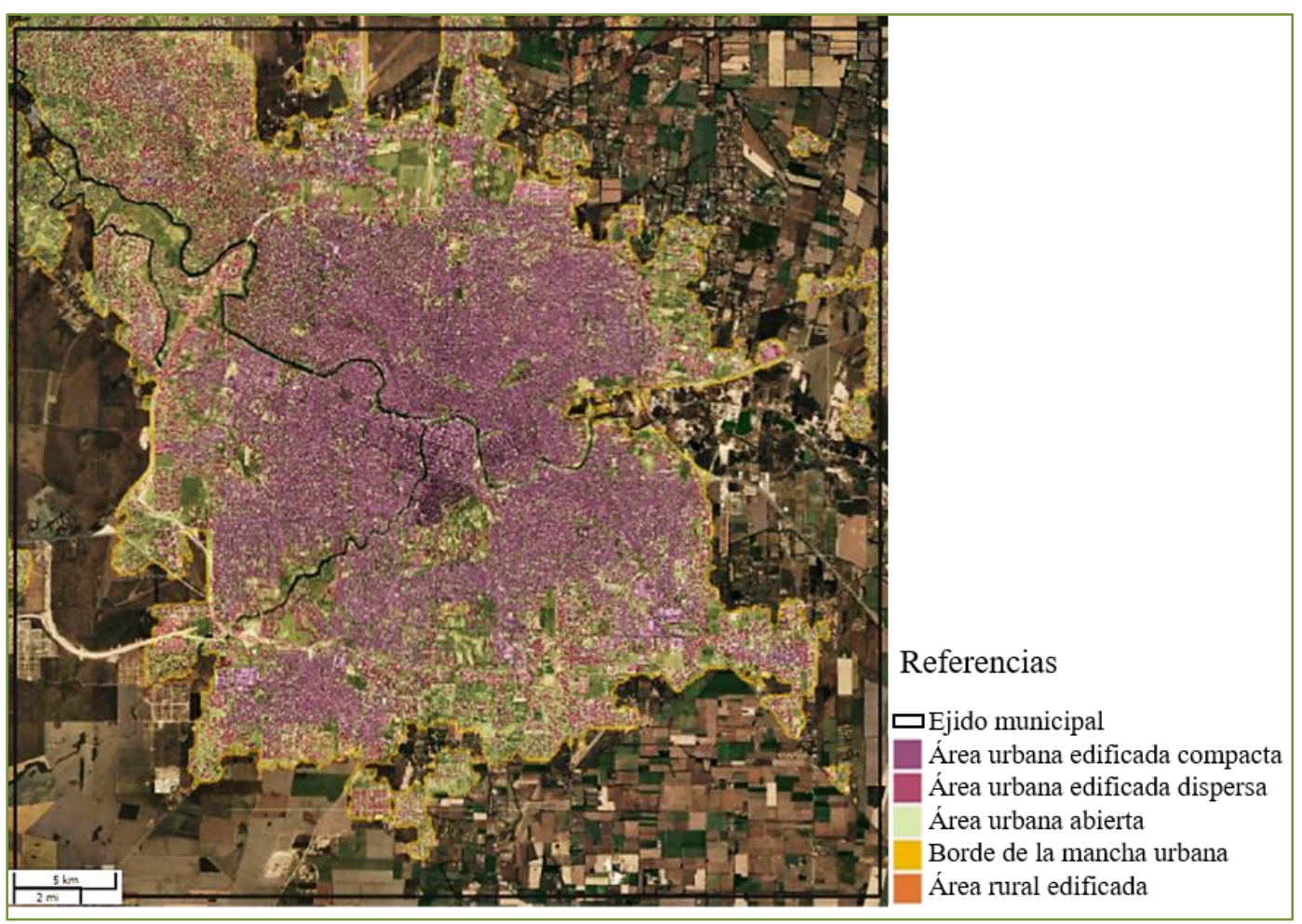

Fuente: adaptado de Infraestructura de Datos Espaciales de la Provincia de Córdoba (IDECOR).

\section{La normalización de los Convenios Urbanísticos}

Para comenzar, es importante situar contextual y temporalmente el proceso de institucionalización de CU.

En Argentina, durante los primeros años de este siglo, la construcción y el negocio inmobiliario se posicionaron como la primera opción para depositar los excedentes y ganancias de los sectores beneficiados por la devaluación resultante de la crisis política-institucional y económica entre 2001-2003 (IERIC 2005). La renta agrícola extraordinaria obtenida gracias a los precios de las commodities ${ }^{6}$ en el plano internacional, sumado a la devaluación de la moneda y la crisis de confianza en el sistema financiero en el plano nacional se configuraron como aliados estratégicos para la actividad constructiva-inmobiliaria que se convirtió en el principal refugio de inversión. Sumado a ello, gracias a la devaluación de la moneda local se generó un incremento de los costos de construcción en pesos a un menor nivel que la valorización del dólar. Contrariamente, los precios de venta de los inmuebles registraron aumentos significativos en pesos ${ }^{7}$, incluso llegando a alcanzar niveles similares al valor en dólares

6 Se habla de commodities para referirse a materias primas o bienes primarios, con bajo nivel de especialización e industrialización que alcanzan valores comerciales iguales en los mercados del mundo.

7 Este proceso se encuentra anclado al alto grado de dolarización que presenta el mercado inmobiliario en Argentina desde la década del 70 (Gaggero y Nemiña 2013), ya que gran parte de los inmuebles se comercializan en dólares americanos a pesar de que los costos de construcción se manejan en moneda local. 
durante el período del "l a l"8. La suma de estas variables permitió una evolución positiva y una recuperación notable de la industria llegando a duplicar los porcentajes interanuales entre 2003-2008 y alcanzando la denominación de "boom inmobiliario" (IERIC 2016). Fenómeno que provocó un cambio en el patrón de oferta y demanda respecto de años anteriores, ya que se convirtió en una estrategia de capitalización de activos, reserva de valor y especulación de grupos de mayores ingresos con posibilidades de inversión y concentración de propiedades. Por ello también, se registraron cambios en las características de los productos ofrecidos al mercado dada las nuevas condiciones de los destinatarios (ibid.) y del modelo de negocios ligado al "desarrollo urbano". En este contexto, en 2004 se crea en la ciudad de Córdoba la Cámara de Desarrollistas Urbanos ${ }^{9}$ de la Ciudad (Ceduc), una entidad que agrupa a los empresarios, institucionaliza su participación con carácter gremial y le da mayor alcance a los reclamos del sector.

Simultáneamente, la agenda regional en torno a la gestión urbana fue invadida por recomendaciones orientadas a la planificación sectorial y la formulación de grandes proyectos urbanos acompañados por diferentes modalidades de vinculación público-privada. Mediante la circulación de estas experiencias bajo el formato de "buenas prácticas", se favoreció la internacionalización y reproducción de dichas modalidades de producción urbana (Jajamovich 2018; 2017). Así también, la circulación de documentos acerca del funcionamiento del mercado de suelo urbano y junto con ello la noción de recuperación de plusvalor elaborados por organismos especializados (Maldonado et al. 2006; Amborski y Smolka 2003), alimentó el debate y la implementación de estas ideas. Fundamentalmente, se planteó a los gobiernos locales como actores activos del "desarrollo urbano", capaces de otorgar condiciones particulares a determinados emprendimientos urbano-inmobiliarios con el fin de compartir un porcentaje de la ganancia estimada y obtener con ello ingresos u obras para la ciudad.

En la ciudad, en 2007 y luego de algunos años de mala relación entre el intendente y la Ceduc (LaVoz 2005; Guevara 2006; 2008) se habilitó al interior de la estructura orgánica municipal el Consejo de Planificación Urbanística (CPU) para la consulta y toma de decisión en torno a las políticas urbanas locales, con la participación de representantes empresariales, la propia cámara y académicos. Con esta injerencia y ante el enfriamiento del boom inmobiliario a partir de 2008 por la crisis financiera internacional ${ }^{10}$, los representantes desarrollistas proponen nuevos mecanismos de "promoción para el crecimiento y el desarrollo urbano" con rápida respuesta del gobierno municipal. En este escenario, con el fin de mantener los niveles

8 Se conoce como " 1 a l" al Plan de Convertibilidad vigente en Argentina desde 1991 a 2002, el cual establecía el mismo valor entre el peso nacional y el dólar estadounidense.

9 Esta denominación fue generada por los propios actores empresariales para referirse a su actividad, el desarrollo de proyectos inmobiliarios y urbanísticos.

10 La llamada crisis de las hipotecas "subprime" o burbuja inmobiliaria que fue el origen de la última gran crisis económica financiera internacional, la cual afectó de manera colateral a la producción inmobiliaria local. 
de actividad del sector y coadyuvados por la ausencia de décadas de un plan de ordenamiento territorial en la ciudad, gran parte de los funcionarios públicos vieron con buenos ojos la posibilidad de replicar algunas experiencias regionales intensamente divulgadas.

En 2008, desde el CPU, se propuso y promovió la reglamentación de dos mecanismos que comparten como objetivos atender las necesidades operativas del desarrollo urbano, mantener los niveles de inversión y empleo y ofrecer una fuente de financiamiento al gobierno local a partir de los beneficios negociados. El primero de ellos, denominado "obras complementarias" (Ord. $\mathrm{N}^{\circ} 11.272$, 2007), permite negociar mejoras en los índices de ocupación y construcción para las operaciones inmobiliarias ubicadas en barrios peri centrales a cambio de obras para el municipio (infraestructura vial, de desagües, cloacas, alumbrado público u otras que resulten necesarias según informes técnicos de las áreas municipales de competencia). El segundo refiere al primer Convenio Urbanístico (Ord. $\mathrm{N}^{\circ} 11545,2008$ ) sobre la base de la concertación público-privada para la negociación de las condiciones normativas y la recuperación de plusvalor a partir del salto de renta del suelo urbano.

Nos concentraremos ahora en el proceso de normalización de los CU. Hasta el momento de la firma del primer CU en 2008, la empresa involucrada -Edisur S.A.-, se abocó a desarrollar edificios para vivienda en altura en las zonas de mayor renovación de la ciudad junto con condominios y loteos para barrios cerrados en el área periférica. Además, tenía entre sus directores a quien también era presidente de la Ceduc en ese momento. Para la fecha, la empresa contaba con la aprobación municipal para ejecutar un barrio cerrado -tipo country- a partir del fraccionamiento de una porción importante de tierra $(62,70$ ha) en la zona sur de la ciudad, bajo las condiciones normativas vigentes de acuerdo a su ubicación (Urbanización Residencial Especial, Ord. $\left.\mathrm{N}^{\circ} 8606 / 91\right)$. La norma permite lotes no menores a $1000 \mathrm{~m} 2$, restricciones de uso no residencial y un porcentaje no menor a $30 \%$ de la superficie destinada a espacios verdes. El CU le permitió a la empresa mejorar las condiciones de uso, fraccionamiento y ocupación del suelo urbano, al optimizar notablemente las condiciones y rentabilidad del desarrollo inmobiliario. A partir de su aprobación, se habilitó a fraccionar el mismo predio en lotes desde los $250 \mathrm{~m} 2$, uso comercial, edificaciones en altura y mayores índices constructivos (Ord. $\mathrm{N}^{\circ} 11545,2008$ ).

En el acuerdo se define que, en base al comportamiento del mercado de suelo urbano e inmobiliario, la aplicación de las nuevas condiciones normativas genera una diferencia a favor de la empresa -denominada en el convenio como plusvalía- y ante la cual el municipio reclama un porcentaje por permitir dichos cambios. El cálculo se aplicó bajo "criterios económicos-comparativos" que determinó la diferencia entre la rentabilidad neta del proyecto original y la del proyecto resultante, teniendo en cuenta la cantidad de lotes y precios de venta, descontando costos de comercialización, obras de infraestructura para la urbanización y gestión. De acuerdo al documento, correspondía una "devolución por beneficios" equivalente a poco más de 
US $\$ 3.000 .000^{11}$, los cuales se deben volcar en obras de infraestructura vial y urbana en inmediaciones al proyecto en cuestión, sumado a la construcción de dos dispensarios en barrios aledaños (LaVoz 2008). El convenio estableció un plazo máximo de cinco años para realizar las obras y de diez para la finalización del desarrollo inmobiliario (imagen 2). El texto incluye una extensa descripción de las condiciones, análisis de factibilidad de diferentes entes de servicios y áreas técnicas del ejecutivo municipal, obligaciones contraídas por ambas partes, obras a realizar como metodología de "devolución" por los beneficios normativos, plazos de ejecución, condiciones de etapabilidad y de la devolución del plusvalor, entre otros.

Imagen 2: Localización del desarrollo inmobiliario bajo el primer CU entre el municipio de Córdoba y la empresa Edisur. (Ord. N¹1545, 2008).

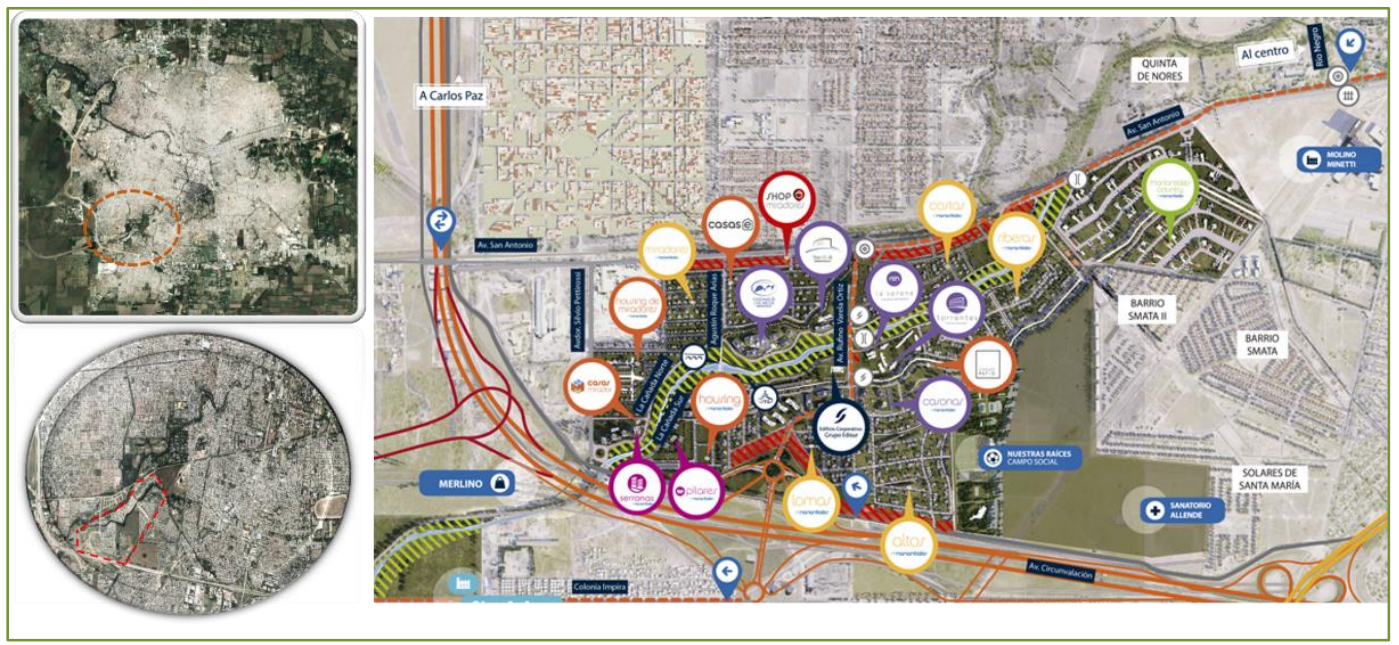

Fuente: elaboración propia de acuerdo a documentos de la empresa y base Google maps.

A la luz de la seguidilla de CU de los años posteriores, tanto la extensión del análisis como el detalle de costos y beneficios que se ejecutó en este primer caso no se repetirá, siendo presentaciones y evaluaciones mucho más austeras. Sin embargo, este primer CU fue determinante en varios aspectos. Por un lado, sentó precedente en la gestión urbana local al generar un espacio de negociación particular respecto al fraccionamiento, usos y edificación del suelo entre el municipio y una empresa desarrollista. Espacio que luego fue aprovechado por muchos otros empresarios e inversionistas que vieron en este mecanismo una oportunidad de negocio. Por otro lado, esta operación significó un salto de escala para la empresa, tanto en su organización administrativa como en su plan de negocios, proceso que hasta la fecha se encuentra en reestructuración (cuadro l).

11 \$10.000.000 que, a cotización del dólar a julio de 2008 según el Banco Central -fecha de la firma del acuerdo- equivalen a US\$3.278.688. 
Cuadro 1: Trayectoria empresarial de Edisur entre 2000 y 2019 y la incidencia de las operaciones mediante CU en la escala y rol de la empresa.

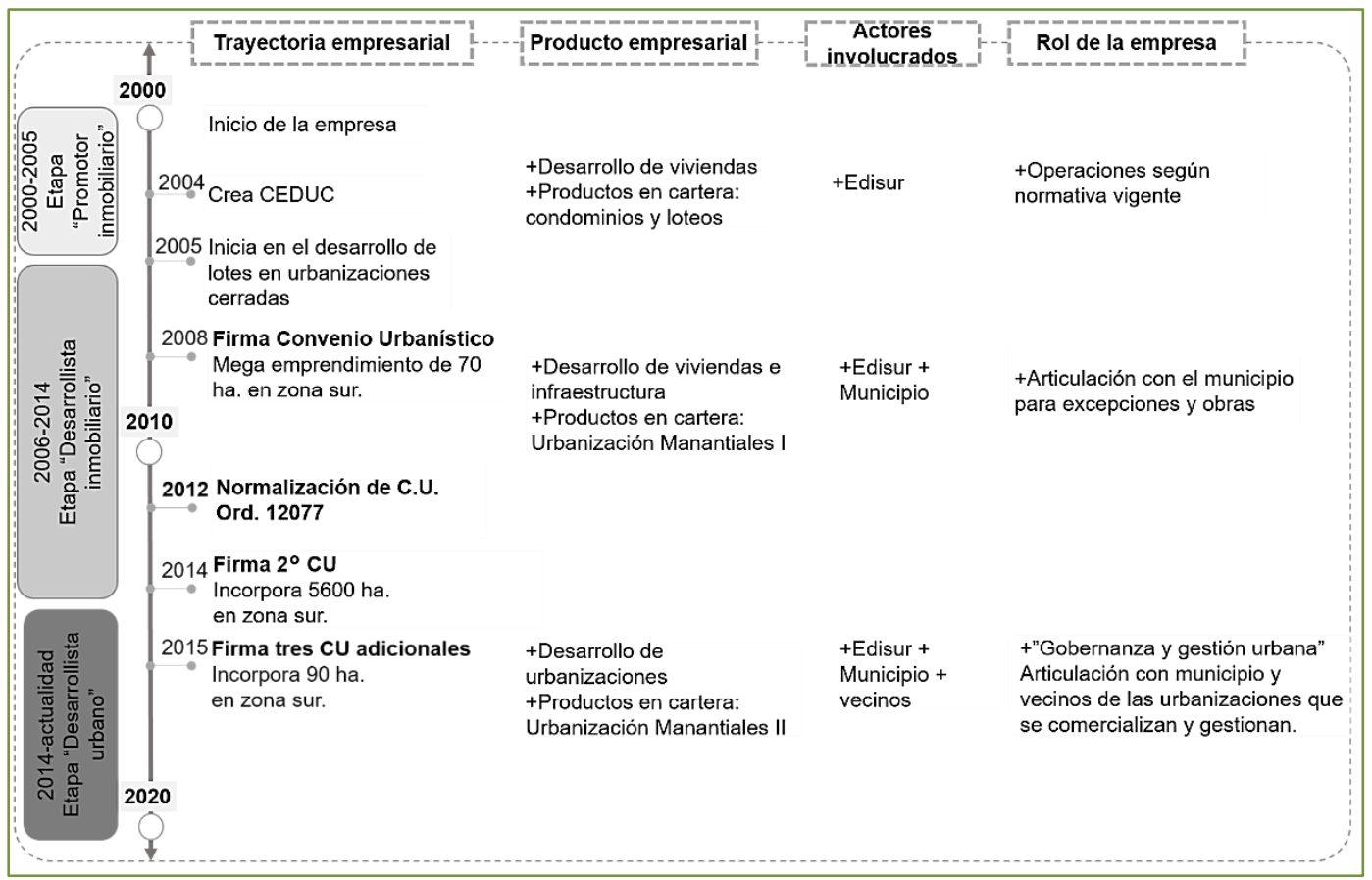

Fuente: elaboración propia de acuerdo a documentos de la empresa.

Luego de este primer convenio, los funcionarios y empresarios vinculados realizaron declaraciones en medios gráficos para instalar el tema en la agenda pública y lograr consenso y legitimización. El relevamiento acusa una sucesión sistemática de notas, desde julio de 2010 hasta su aprobación y normalización como herramienta en septiembre de 2012, en favor de los Convenios Urbanísticos y de la estrategia de concertación que avaló la gestión local; que incluso atravesó un cambio de partido en el gobierno local y el recambio de todos los funcionarios del área de desarrollo urbano.

El proceso iniciado en 2007 se concreta en 2012 con la normalización de este mecanismo bajo la Ord. $\mathrm{N}^{\circ} 12.077$, con una administración municipal de diferente color político, pero que a la luz de los hechos, mantuvo el mismo enfoque respecto de la gestión urbana. La ordenanza regula y estipula las condiciones mínimas para celebrar CU entre "el municipio y las personas físicas y/o jurídicas de carácter público y/o privado", en lo relacionado con el fraccionamiento, uso y ocupación del suelo en el ejido de la ciudad. Presenta como objetivos instrumentar mecanismos jurídicos, administrativos y económicos-financieros, que doten al gobierno municipal de las herramientas necesarias para favorecer el desarrollo de la ciudad y promover la inversión privada, como también fomentar la cooperación entre los distintos sectores para la realización de proyectos, gestión de áreas o servicios urbanos y en función de ello alcanzar transformaciones urbanísticas y estructurales con mayor rapidez de ejecución y menor afectación de recursos públicos.

Los CU son iniciados por aquellos interesados en "requerir la modificación de las normas vigentes" con el fin de "viabilizar una intervención". Las modificaciones solicitadas son evaluadas y aprobadas por el cuerpo técnico municipal, constituyendo un mayor beneficio para la operación entendiendo por tales a las "mejoras en su 
aprovechamiento y utilización" las cuales deberán ser "compartidas entre el Municipio y el iniciador" (Ord. $\mathrm{N}^{\circ} 12077,2012$ ). La definición del beneficio, el porcentaje de participación del municipio y el destino de los fondos obtenidos se establecen de manera particular y ad hoc en cada CU bajo la única premisa de recuperar porcentajes mínimos entre el 10\% (mejoras sobre índices constructivos) y el 15\% (en caso de que sean cambios en las condiciones de uso y fraccionamiento del suelo) de las ganancias extras otorgadas por las nuevas condiciones normativas. Esta definición será modificada en el año 2018 (Ord. $\mathrm{N}^{\circ} 12.887$ ), al incorporarse nuevas variables para la generación de beneficios y una fórmula para su cálculo. Queda omitido en la norma establecer áreas estratégicas o prioritarias para la implementación de estos convenios, como tampoco se determina la necesidad de cercanía con áreas urbanizadas dejando a merced de los empresarios inmobiliarios solicitar modificaciones de las normas de uso, fraccionamiento y ocupación del suelo en cualquier zona de la ciudad.

\section{La etapa de implementación}

Luego de su normalización en 2012, se registró una aprobación masiva de 31 CU hasta la fecha, de acuerdo al relevamiento, los cuales se agrupan en tres ciclos temporales (figura 1) a los fines de este análisis.

El primer ciclo de implementación se identifica entre 2012 y 2013 e incluye dos convenios (Ord. $\mathrm{N}^{\circ} 12.148$ y 12.150 ), relacionados a proyectos de grandes empresas desarrollistas a nivel nacional que ya estaban en cartera e incluso habían entablado negociaciones previas con el gobierno anterior. El primero dentro de este ciclo, se inició en enero de 2013 por la empresa Corporación América S.A. El CU incluyó el cambio de uso del suelo e índices constructivos sobre un espacio verde de ubicación estratégica en la ciudad a cambio de la construcción de una planta de tratamientos cloacales. Este convenio provocó gran repercusión mediática, incluso hasta la actualidad, dado su recorrido sinuoso y polémico a lo largo de los años al involucrar a una empresa de gran magnitud y de escala internacional, las características del proyecto que se intenta construir (imagen 3) y la falta de cumplimiento de los beneficios acordados hasta la fecha (Giannoni 2016; LaVoz 2017; 2016). Este es el CU que más repercusión ha tenido, con presentaciones en audiencias públicas y reclamos por parte de vecinos y organizaciones civiles. 
Imagen 3: Pre visualización del proyecto aprobado en el CU con Corporación América (Ord. No12148).

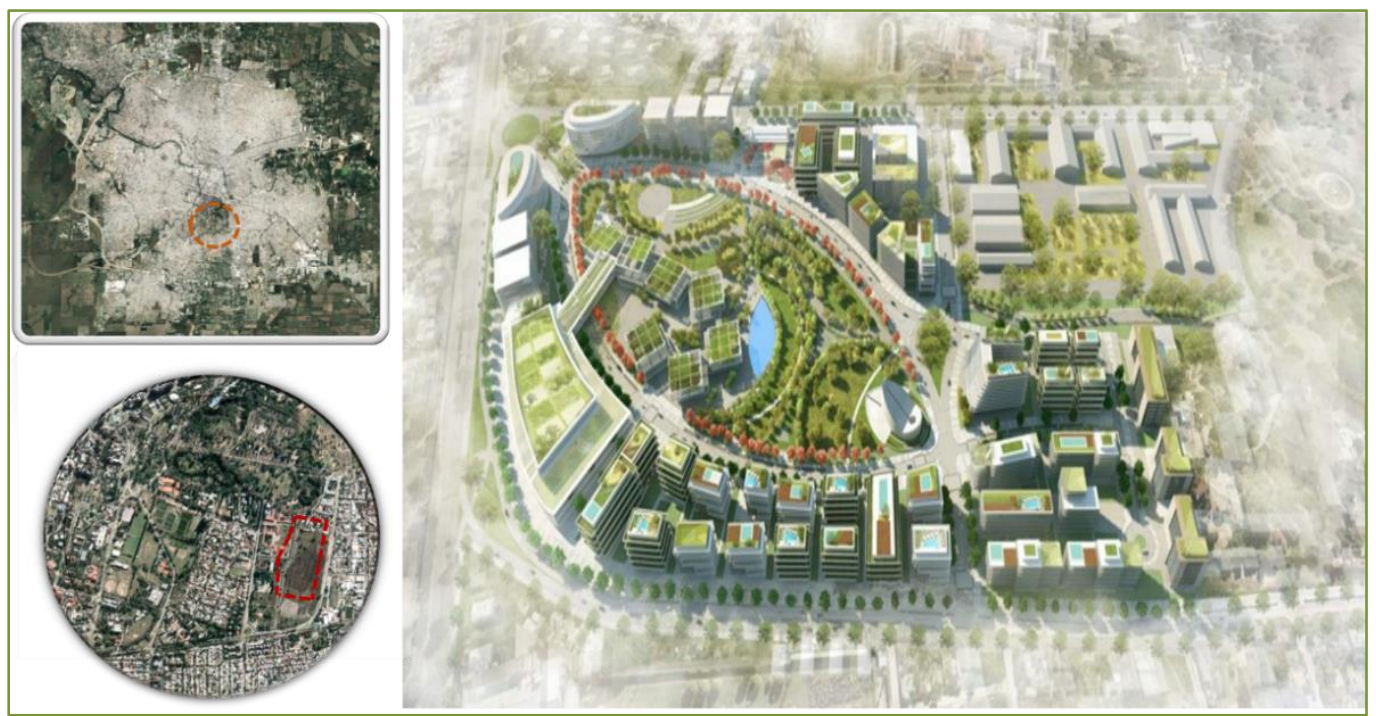

Fuente: Página web de "Corporación América". Emprendimiento "Distrito las artes" http://gorealestate.com.ar/project/distrito-las-artes/ (consulta: agosto 2019)

El CU admitido en diciembre de 2013 con Estancia Los Ombúes (empresa Proaco), marca el inicio de un nuevo ciclo que implicó fundamentalmente una serie de convenios con modificaciones en las condiciones de uso, fraccionamiento y ocupación de suelo localizado en la periferia de la ciudad y que involucró a empresas desarrollistas locales e inversionistas que lograron materializar una oportunidad de negocio. Lo particular de este CU es el salto de escala, tratamiento y definición, ya que se trató de un cambio de uso del suelo de más de 700 ha en el borde del límite político administrativo de la ciudad, siendo una zona de explotación rural y sin conexión con la mancha urbana (imagen 4).

Imagen 4: Localización del desarrollo inmobiliario bajo el primer CU entre el municipio de Córdoba y la empresa Proaco-Establecimiento Los Ombúes (Ord. N¹2276, 2013).

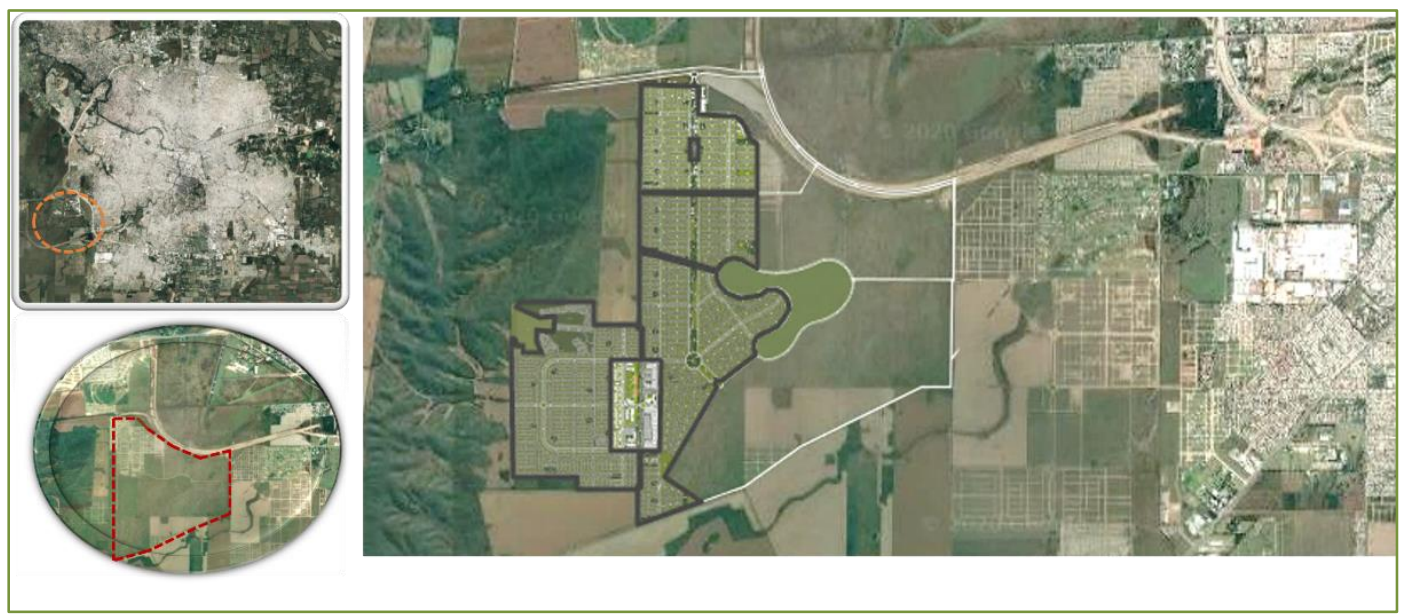

Fuente: elaboración propia de acuerdo a documentos de la empresa y base Google maps. 
El convenio le permitió a la empresa, que hasta la fecha solamente había desarrollado edificios de viviendas en altura y condominios, urbanizar 700 ha en lotes de $250 \mathrm{~m}^{2}$ y $360 \mathrm{~m}^{2}$ en un área rural, que en las condiciones normativas vigentes no debía contar con fracciones menores a los $5000 \mathrm{~m}^{2}$. Ante este beneficio, se otorgó como devolución al municipio la sesión de una fracción de tierra para la realización de un parque público dentro del mismo emprendimiento. Este acuerdo se destacó por ser la intervención bajo CU con mayor incidencia en superficie, orientar el uso posterior de su implementación y generar una división entre quienes la apoyaban, incluso hacia adentro de la propia gestión. Además, marcó el inicio de una serie de CU que van a signar y caracterizar el uso del instrumento, lo que generó oposición en los cuadros técnicos del municipio (Zen 2013). La caracterización de este segundo ciclo, se completa además de la intervención sobre suelo rural y periférico, por la "masificación" que se produce entre diciembre de 2013 y finales de 2015, ventana de tiempo en la cual se aprobaron más de veinte CU (figura 1).

"Al CU te lo defiendo a muerte, porque es un instrumento ágil que te permite hacer proyectos de impactos significativos. Cómo se usa, no me hago cargo.

(...) Lo que pasa es que tiene dos patas. Lo que pasa hacia adentro de la ciudad, los proyectos de renovación y lo que pasa hacia afuera, los proyectos de extensión o de anexión de suelo urbano. Esos proyectos, yo no estaba en el departamento de planificación cuando se aprobaron, entre 40 5, en realidad entre dos fundamentalmente Docta y Edisur suman 1000 ha nuevas de suelo urbanizable. Esos CU no los defiende nadie. Fueron acuerdos (...) que no se justifican, no hay estudios que ameriten ese tipo de desarrollo en el corto plazo, el nivel de monopolización del suelo, con la gran extensión, sin etapabilidad" (director de subsecretaría de planificación, entrevista, 31 de octubre de 2018).

En este ciclo encontramos también CU iniciados tanto por desarrollistas locales ya constituidos y con trayectoria (entre ellos, varias de las empresas integrantes de la Ceduc), como por asociaciones temporales bajo la figura de fideicomiso ${ }^{12}$, creados para la realización de proyectos inmobiliarios con el fin de explotar la oportunidad de negocio. Entre los más destacados, por la escala de las intervenciones además del acuerdo señalado anteriormente, se encuentran dos convenios con una cooperativa de vivienda reconocida en la ciudad y cuatro convenios iniciados nuevamente por la empresa Edisur que, en suma, van a urbanizar, desarrollar y comercializar una gran porción de suelo localizada en el sector sur-oeste de la ciudad (Imagen 5). En síntesis, la localización, tipo de iniciadores, escala de las operaciones y superficies afectadas como también la particular valoración de la participación del municipio en los

12 El fideicomiso inmobiliario es un contrato (figura jurídica ley nacional 24.441/94) en el cual una persona, el fiduciante, se obliga a transmitir a otra (fiduciario) una determinada cantidad de bienes para que éste los administre durante un cierto tiempo o hasta el cumplimiento de una determinada condición, con el encargo de transmitirlos al cumplimiento de ese tiempo o de esa condición a una tercera persona llamada beneficiario. Este instrumento es ampliamente utilizado en Argentina para desarrollar emprendimientos inmobiliarios con fondos de terceros. Los inversores son fiduciantes que aportan los fondos para hacer frente a los costos del proyecto dejándolos protegidos, ya que el patrimonio del fideicomiso solo responde por las deudas generadas en el propio negocio y no es atacable por acreedores particulares de las partes. 
beneficios y el corto periodo de tiempo en el que se dictaron informes de aprobación para todos ellos durante este ciclo, señalan las características singulares en el uso de este mecanismo.

Imagen 5: Geolocalización de proyectos beneficiados por Convenios Urbanísticos según fecha de aprobación entre 2012 y 2019 . Ciudad de Córdoba.

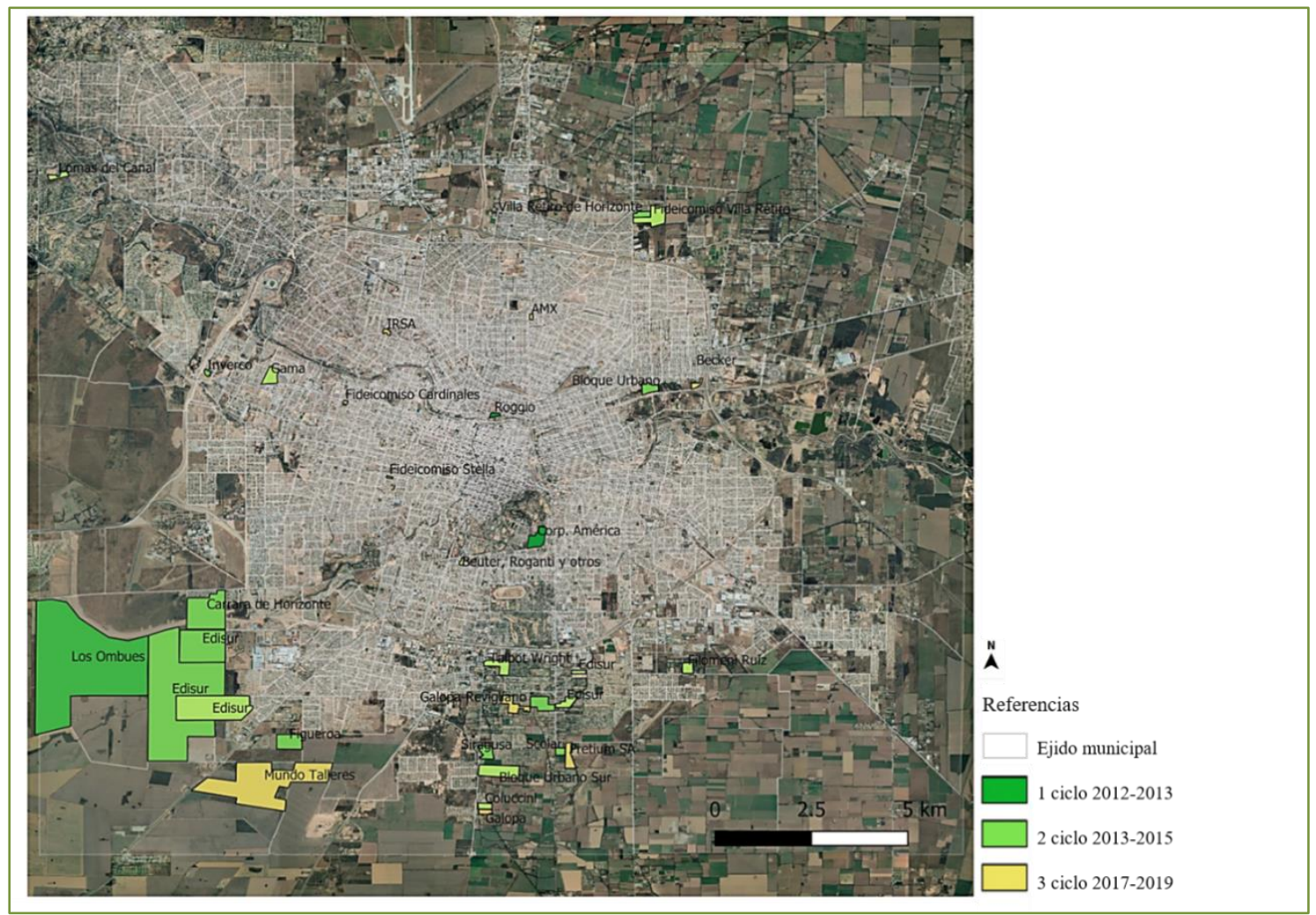

Fuente: Elaboración propia en base a digesto municipal y registro de Convenios Urbanísticos de la Municipalidad de Córdoba a diciembre de 2019.

Para finales de 2014 y bajo nuevas autoridades (por un cambio de funcionarios como consecuencia de una serie de denuncias de corrupción que obligó al intendente a pedir la renuncia de su gabinete-LaVoz 2014), se sucedieron una serie de nueve convenios de pequeña envergadura, la mayoría de asociaciones y fidecomisos generados exclusivamente para ello, los cuales involucraron el cambio de uso del suelo en predios cercanos al límite jurisdiccional.

Durante 2016 y hasta finales de 2017 se identificó un período en el cual no se aprobó ningún convenio, dejando un vacío temporal. Esta ventana coincide con la renovación de la gestión municipal en diciembre de 2015, que ante los conflictos generados vio oportuno realizar un cambio de nombres entre los funcionarios encargados de las áreas operativas. Sin embargo, durante el mismo lapso, se registraron numerosas adendas a los acuerdos ya aprobados, prorrogando los pazos de aplicación y ejecución de las obras comprometidas como beneficios.

El tercer y último ciclo, dado que no se registraron nuevos $\mathrm{CU}$ a la fecha de esta publicación, se identificó entre diciembre de 2017 y septiembre de 2019. En él, se aprobó el único CU destinado a un uso distinto al residencial (habilitó mayor superficie 
construible a un depósito industrial) y sumó como iniciadores a un club deportivo de gran importancia y a una empresa desarrollista de escala internacional (IRSA S.A.).

Figura 1: Evolución temporal de la implementación de CU según fecha del acuerdo. Ciudad de Córdoba, 2008-2019.

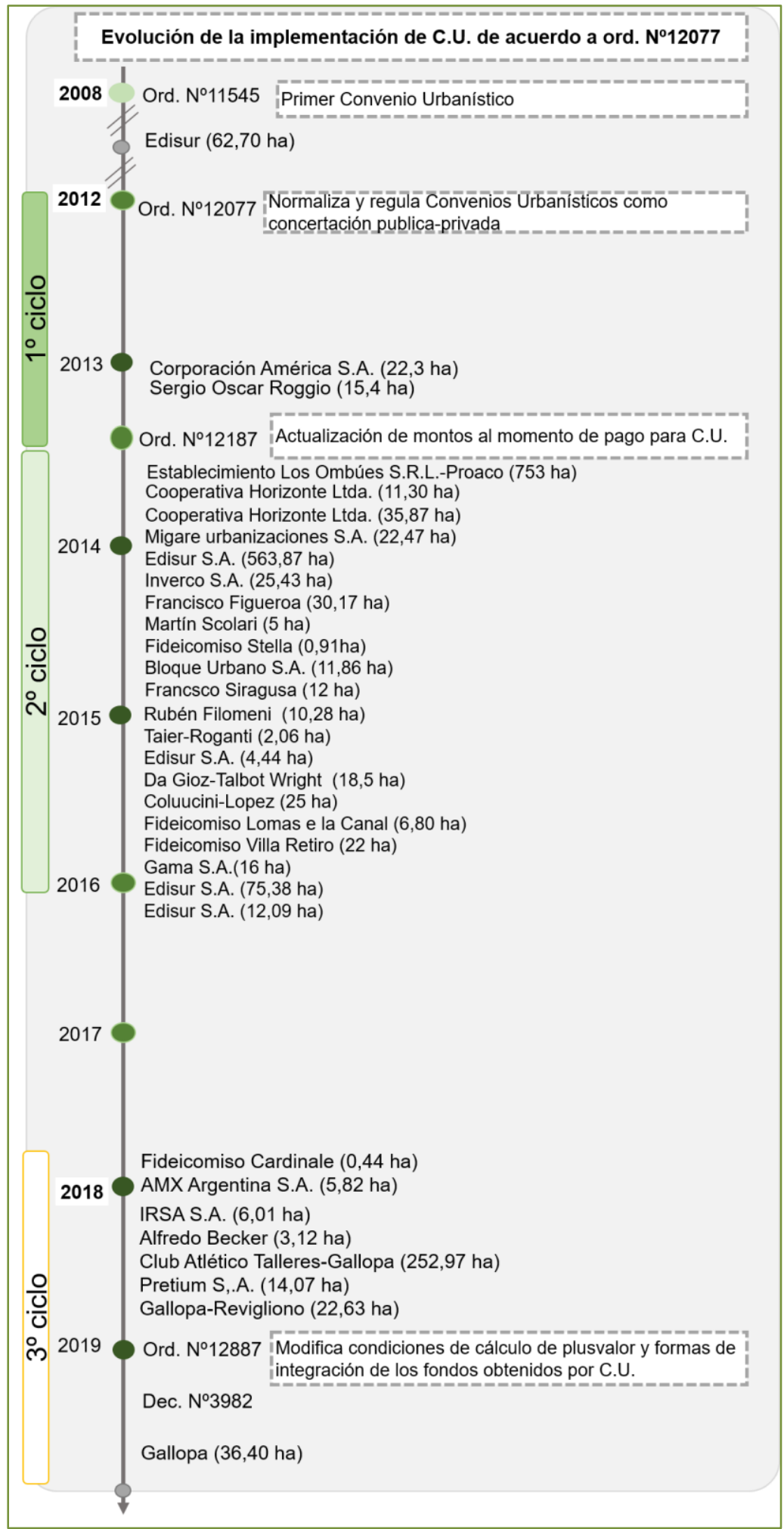

Fuente: Elaboración propia en base a digesto municipal y registro de Convenios Urbanísticos de la Municipalidad de Córdoba a diciembre de 2019. 
Respecto del destino de los beneficios obtenidos por CU y de acuerdo al texto de cada convenio, se establece por recurrencia, la priorización en la ejecución de obras viales y de infraestructura. Con una notable menor repetición aparecen: construcción de equipamientos sociales (como dispensarios), donaciones de polígonos de tierra destinados a espacios verdes y calles y, por último, dinero en efectivo destinado a un fondo de reparación urbanística. Apenas en una ocasión se destina la sesión de fracciones de tierra, materiales y/o dinero para viviendas de emergencia, del cual no se pudieron obtener datos de localización o cantidad ejecutadas. Por otro lado, de los acuerdos firmados en 2013 a pesar de haber pasado holgadamente los plazos (máximo de 2 años para concretar los beneficios al municipio), las obras se encuentran sin iniciar o "en ejecución". A diferencia, los CU aprobados en el segundo ciclo (2014-2015) cumplen mayoritariamente con los plazos de obras, pagos o transferencias de tierras según el caso. De los CU firmados entre 2017 y 2019, en su extensa mayoría las obras se encuentran sin iniciar de acuerdo a los registros. A pesar del plazo dispuesto en la ordenanza para el comienzo de las obras acordadas, con potestad del municipio de disolver el acuerdo sin que esto genere reclamo alguno, no se ha registrado ningún tipo de solicitud por las demoras o el incumplimiento de plazos más allá de la incorporación de anexos a los convenios aprobados para salvar estas faltas.

\section{En torno a la legitimidad de los Convenios Urbanisticos}

Desde el sector empresarial se presenta repetidamente como argumento a favor de sus reclamos que la regulación estatal encarece los productos inmobiliarios, apoyado en la idea de que la dificultad en el acceso a la vivienda o un lote urbano es resultado de la normativa impuesta por el municipio y que una flexibilización en ese sentido abarataría los productos. Para su beneficio, se arrogan la capacidad de generar inmuebles para la venta y facilitar el acceso de la clase media, generar empleo, movilizar recursos, todo ello acompañado del permanente pedido de reducción burocrática y flexibilización de las exigencias normativas dada la posición que ostentan como constructores o "desarrolladores urbanos".

Por parte del gobierno local se repite la necesidad de financiamiento del municipio como razón válida para la normalización y uso de los CU, asumiéndolos fundamentalmente como una vía para obtener fondos. De acuerdo al registro, los montos acordados como beneficios, incluyendo obras, dinero en efectivo y materiales (no se registran los montos equivalentes al valor de las sesiones de tierra) han sido muy dispares e incluso se registra un valor cero en el año 2016. De acuerdo al registro elaborado, el financiamiento total alcanzado a través de CU entre 2012 y 2018 equivale en promedio al 7,44\% del presupuesto anual destinado a las áreas de desarrollo urbano e infraestructura. Comparativamente, los ingresos obtenidos no logran configurar en cantidad ni en proyección temporal, una fuente de financiamiento estable para el gobierno local (gráfico 2). Las obras conseguidas son escasas, de pequeña escala y apuntan al mantenimiento de la red vial y equipamiento de servicios a nivel barrial, muchas veces beneficiando las zonas donde se ejecutan las operaciones inmobiliarias. 
Por el contrario, la implementación de este mecanismo se convirtió en una excelente fuente de financiamiento para las empresas desarrollistas involucradas, otorgándole ganancias extraordinarias tanto por la captura del salto de renta ruralurbano como por la habilitación para el fraccionamiento de lotes de menor superficie de acuerdo a la normativa. Sumado a ello, se puede reconocer que a partir de las operaciones a través de CU tanto las condiciones de la oferta de suelo urbano como su propiedad quedan concentradas fundamentalmente en manos de dos empresas locales y miembros de la Ceduc. Una situación que les permite establecer las condiciones de la oferta de suelo urbano en los próximos años, mientras tengan en comercialización las urbanizaciones desarrolladas.

Gráfico 2: Comparación de ingresos por gasto institucional según presupuestos anuales y CU entre 2007-2019. Ciudad de Córdoba. Absolutos, en millones de pesos.

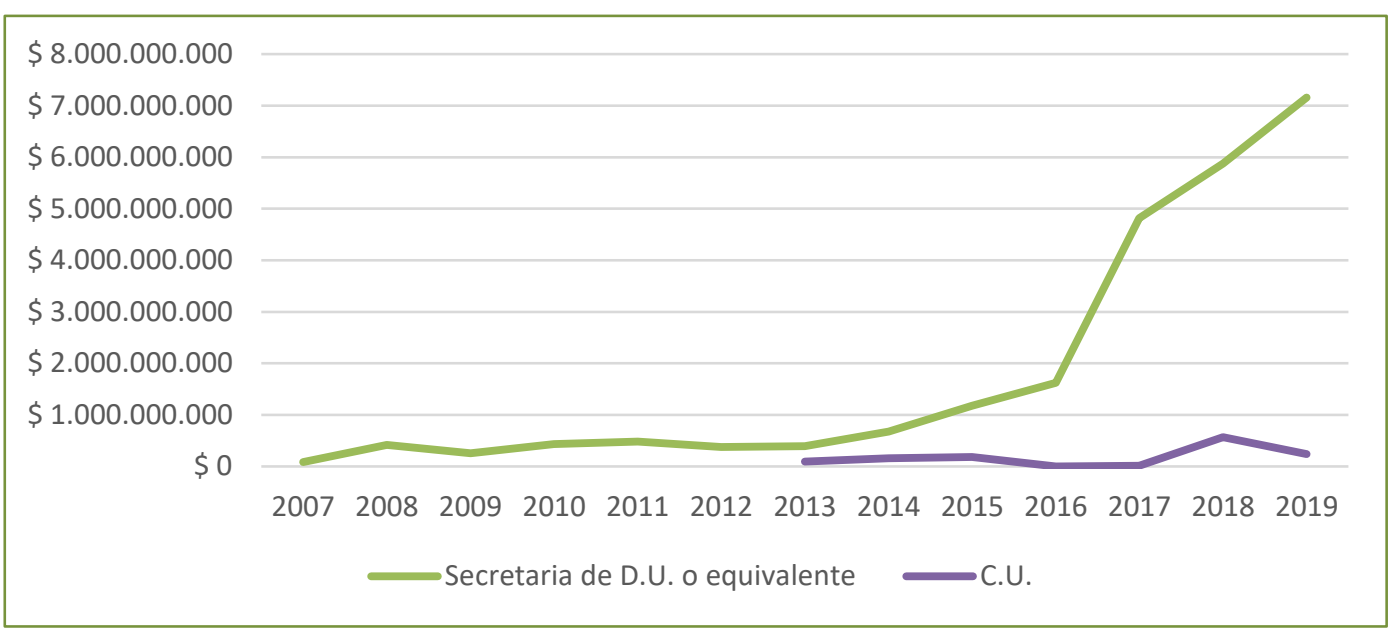

Fuente: Ordenanzas de presupuesto anual y Secretaría de economía y finanzas. Municipalidad de Córdoba.

No quedan dudas por la escala y cantidad de las intervenciones, que el funcionamiento y conformación de la ciudad se verá afectado, aunque aún no se logre establecer con claridad cuáles serán las consecuencias para la ciudad ni cuánto tiempo llevará, dado que los plazos de ejecución de las operaciones inmobiliarias están vigentes y en muchos casos involucran planes de negocio a mediano y largo plazo.

\section{Resultados económicos y políticos}

Según datos oficiales se incorporaron 1.730 hectáreas de suelo urbano habilitado para su ocupación y construcción en la ciudad, antes destinado a uso rural o industrial. En gran parte, quien ha capturado el salto de renta ha sido el sector desarrollista inmobiliario. Coincidentemente, las urbanizaciones con mayor superficie e impacto habilitadas gracias a los CU pertenecen a los grupos desarrollistas de mayor concentración. Con esto, el cuadro de actores que manejan los valores del suelo urbano tiende a consolidarse y condensarse en un pequeño y selecto grupo asociado directamente al complejo inmobiliario-financiero. Podemos decir entonces que la operativización de los CU se tradujo en una cuantiosa producción de suelo urbano, 
otorgando el rol creador a agentes privados más allá de las proyecciones poblacionales e incluso de la demanda, apuntando además a consolidar la concentración de la oferta y las modalidades de producción de suelo urbano en la ciudad en un puñado de empresas.

Las presiones e influencia de los grupos empresarios sobre los espacios de decisión gubernamental son determinantes para el desarrollo de este proceso, lo que llamamos la gobernanza urbana empresarialista realmente existente. La Ceduc ha demostrado funcionar como una estrategia eficiente, ya que a través de la organización empresarial organizada (Dossi 2012) han canalizado sus intereses, posiciones y demandas logrando influencia en el plano político-institucional y un espacio privilegiado respecto de otros actores sociales en el ámbito gubernamental local. El sector inmobiliario, respaldado por intereses económicos financieros, logró legitimar un mecanismo que les permite generar inversiones seguras y de alto rendimiento.

Los CU se presentan como un instrumento de gestión urbana novedoso y oportuno, de hecho, estos instrumentos han sido promovidos bajo la idea de generar autonomía presupuestaria y poder de acción a los municipios además de considerarlo una opción justa y socialmente legitimada para la captación de recursos. Sin embargo, las condiciones expuestas en el caso de análisis pueden ser leídas como las condiciones realmente existentes en las que se desenvuelven estos mecanismos en los gobiernos locales de la región, y con ello también cómo se materializa la financiarización de la gestión urbana en el marco del proceso de neoliberalización. Respecto a ello, estas experiencias instalan cambios sustanciales en el rol del gobierno local sobre la regulación de lo urbano y en las condiciones legales, técnicas e institucionales en las cuales se habilitan y desarrollan las operaciones inmobiliarias. Transformaciones que, al mismo tiempo, legitiman la necesidad y responsabilidad gubernamental de sostener el "desarrollo urbano", ligado casi exclusivamente a brindar garantías a las empresas para su buen funcionamiento y rentabilidad. En este escenario, la normalización e implementación de CU señala la necesidad de la administración municipal de perseguir la renta urbana como fuente de financiamiento mediante la mercantilización de la capacidad decisoria-normativa y con ello ratificar la lógica financiera en la gobernanza urbana (cuadro 2). 
Cuadro 2: Ingresos obtenidos por CU en la ciudad de Córdoba entre 2008 y 2019.

\begin{tabular}{|c|c|c|c|c|c|}
\hline Instrumento & $\begin{array}{l}\text { Escala de } \\
\text { intervención }\end{array}$ & $\begin{array}{l}\text { Beneficios según } \\
\text { reglamentación }\end{array}$ & $\begin{array}{l}\text { Intensidad de } \\
\text { aplicación }\end{array}$ & $\begin{array}{l}\text { Superficie } \\
\text { Afectada }\end{array}$ & $\begin{array}{l}\text { Importe para el } \\
\text { municipio }\end{array}$ \\
\hline $\begin{array}{l}\text { Convenios } \\
\text { Urbanísticos }\end{array}$ & $\begin{array}{l}\text {-Por lote y por área } \\
\text { (posibilidad } \\
\text { de modificar } \\
\text { condiciones de } \\
\text { grandes fracciones } \\
\text { a pedido de los } \\
\text { iniciadores) }\end{array}$ & $\begin{array}{l}\text { - 10\% por mejores } \\
\text { índices constructivos } \\
\text {-15\% por cambio en } \\
\text { el uso, fraccionamiento } \\
\text { y ocupación del suelo }\end{array}$ & $\begin{array}{l}2007-2011 \\
1 \mathrm{CU} \\
2011-2019 \\
31 \mathrm{CU}\end{array}$ & $\begin{array}{l}2007-2011 \\
63 \text { ha } \\
2011-2019 \\
2082 \text { ha }\end{array}$ & $\begin{array}{l}2007-2011 \\
\$ 42.178 .920 \text { (Cotización del } \\
\text { dólar entre } \$ 3,10 \text { y } \$ 4,28 \text { ) } \\
2011-2019 \\
\$ 1.615 .568 .592 \text { (Cotización } \\
\text { del dólar entre } \$ 4,28 \\
\text { y } \$ 62,25 \text { ) }\end{array}$ \\
\hline
\end{tabular}

Fuente: elaboración propia de acuerdo a documentos oficiales.

Discusión aparte merece la concepción de plusvalor y beneficio aplicado en este caso, por estar colmado de controversias que recaen sobre el entendimiento y la distribución de la renta extraordinaria obtenida. Los excedentes capturados por las empresas desarrollistas al reproducir la capacidad constructiva y de ocupación del suelo han sido desproporcionadamente superiores a los obtenidos por el municipio y aún más, cuando se evidencia que en su mayoría, las obras recuperadas para el municipio tienden a reforzar la valorización de los propios emprendimientos.

\section{Para cerrar}

La financiarización del sector inmobiliario se convirtió en objeto de investigación e interés en el campo de los estudios urbanos, concentrando los análisis en torno a las dinámicas del capital y sus estrategias o mecanismos. La atención se ha focalizado fundamentalmente en comprender los instrumentos financieros utilizados o las maniobras particulares que se ejecutan para ello, dejando de lado los mecanismos y estrategias que han operado desde y hacia las políticas urbanas. En este sentido los gobiernos locales no solamente han debido innovar sus estrategias de financiamiento mediante instrumentos o mecanismos puramente financieros, sino que se han registrado avances en las formas legales e institucionales que involucran la vinculación público-privada para el desarrollo especulativo de operaciones urbano-inmobiliarias.

Este trabajo pone el foco en la aplicación de instrumentos de gestión urbana que basan su estrategia en la mercantilización del marco normativo como recurso de financiamiento bajo el argumento de la concertación público-privada y la recuperación de plusvalor. Mediante la acumulación de evidencias en la actuación local, se intenta exponer que además de las innovaciones instrumentales vinculadas a operaciones financieras o a los circuitos financieros internacionales sustentados en la inversión y la renta urbano-inmobiliaria, aún continua vigente y obteniendo cada vez mayor legitimidad y respaldo institucional una vieja y conocida estrategia de financiarización en base la captura de valor por el salto de renta. Es precisamente su 
normalización y legalización lo que renueva esta estrategia o práctica financiera como valedera y eficaz otorgándole además legitimización institucional, lo que para esta investigación marca una nueva fase del urbanismo neoliberal.

No podemos tampoco desconocer la efectiva influencia que han tenido en este proceso los organismos internacionales a través de la circulación, difusión y replica de "buenas prácticas" relacionadas con la habilitación y legitimización de instrumentos de recuperación de plusvalor. Las recomendaciones se basan en sugerir a los municipios como actores promotores que, al tener el monopolio de la potestad regulatoria, deben capitalizarla como un activo plausible de negociar frente a la necesidad de un mejor rendimiento y productividad de las inversiones inmobiliarias. Con ello, la legitimización y uso de este tipo de mecanismos potencia la priorización de los actores empresariales por sobre los demás actores sociales que participan de la producción urbana, lo que Aalbers denomina como "gobernanza urbana financiada"(2020).

Cabe preguntarnos entonces cuáles son las consecuencias de institucionalizar instrumentos como los CU, bajo las ya mencionadas condiciones de normalización e implementación, mientras se desenvuelven como mecanismo de financiarización. Insistimos en que el rol que cumple el gobierno municipal es clave para reconocer y analizar las tendencias del proceso de financiarización urbana. En este sentido retomar las condiciones locales y coyunturales, así como el reconocimiento de los actores que participan, intentando escapar de la neutralidad o la presunción de equivalencia en las capacidades e influencia puestas en juego, podría ayudar a reconocer las virtudes y dificultades que traen aparejadas la normalización y legitimización de este tipo de estrategias. Así mismo, asoma la necesidad de potenciar los análisis en lo que refiere a las condiciones normativas y regulatorias del "desarrollo urbano" y las implicancias de la utilización de diversos mecanismos financieros en la gestión urbana, lo cual resulta fundamental para avanzar en el conocimiento de los efectos de la financiarización en el territorio.

\section{Bibliografía}

Aalbers, Manuel. 2020. "Financial geography III: The financialization of the city". Progress in Human Geography 44 (3): 595-607.

Amborski, David y Martim Smolka. 2003. "Recuperación de plusvalías para el desarrollo urbano: una comparación inter-americana". EURE-Revista Latinoamericana de Estudios Urbanos Regionales XXIX: 55-77.

Araujo, Antonio. 2010. "Las nuevas formas de regulación neoliberal". Hendu - Revista Latino-Americana de Direitos Humanos 1 ( 1): 52-66..

Barenboim, Cintia. 2015. "Análisis de los instrumentos de regulación urbana empleados en Puerto Norte y sus áreas de influencia, en Rosario, Argentina". Revista Ciudades, Estados y Política 2 (1): 1-14.

Benavides, Mayumi y Carlos Gómez-Restrepo. 2005. "Métodos en investigación cualitativa: triangulación." Revista Colombiana de Psiquiatría 34 (1): 118-24. 
Brenner, Neil, Jamie Peck, y Nik Theodore. 2011. “¿Y después de la neoliberalización? Estrategias metodológicas para la investigación de las transformaciones regulatorias contemporáneas". Urban 1: 21-40.

Brenner, Neil y Nik Theodore. 2002. "Cities and the Geographies of 'Actually Existing Neoliberalism'". Antipode 34 (3): 349-79.

Centrangolo, Oscar y Francisco Gatto. 2002. "Las provincias en la crisis Argentina. Algunos elementos para discutir las prioridades de la cooperación internacional". Buenos Aires. CEPAL.

Coremberg, Ariel. 2006. "Fuentes del Crecimiento Económico en Argentina 1990-2004 ¿Otro Caso de la Tiranía de los Números?'. Revista de Economía Política de Buenos Aires 2 (Agosto): 55-88.

Cuenya, Beatriz y Eduardo González. 2017. "Planificación y redistribución de beneficios del desarrollo urbano: la contribución compensatoria en Rosario, Argentina". Revista INVI 32 (90): 77-104.

Delgadillo, Víctor. 2014. "Urbanismo a la carta: teorías, políticas, programas y otras recetas urbanas para ciudades latinoamericanas". Cadernos Metrópole 16 (31): 89-111.

Dossi, Marina. 2012. “Debates sobre la acción empresarial organizada: aportes para la elaboración de la acción corporativa empresaria". Papeles de Trabajo - UNGSM 6 (9): 58-83.

Gaggero, Alejandro y Pablo Nemiña. 2013. “El origen de la dolarización inmobiliaria en la Argentina". Sociales en debate.

Giannoni, Walter. 2016. "Eurnekian invertirá U\$S 1.000 millones en el desarrollo del ex Batallón 141". LaVoz, el 17 de mayo de 2016. http://www.lavoz.com.ar/politica/eurnekianinvertiraus 1000milloneseneldesar rollodelexbatallon 141 .

Guevara, Virginia. 2006. "Córdoba busca su destino urbanístico". LaVoz, el 27 de julio de 2006.

archivo.lavoz.com.ar/NotaAnterior.asp?nota_id=431494\&high=CEDUC.

Guevara, Virginia. 2008. "Giacomino lanza su apuesta a la concertación”. LaVoz, el 9 de marzo de 2008.

archivo.lavoz.com.ar/09/03/08/secciones/grancordoba/nota.asp?nota_id=169605.

Harvey, David. 1989. "From managerialism to entrepreneurialism: the transformation in urban governance in late capitalism". Geografiska Annaler. Series B, Human Geography 71 ( 1): 3-17.

Harvey, David. 2007a. Espacios del capital. Hacia una geografía critica. $1^{\circ}$. Madrid: Akal.

Harvey, David. 2007b. "Neoliberalism as Creative Destruction". The ANNALS of the American Academy of Political and Social Science 610 (1): 21-44.

Hidalgo, Rodrigo, y Michael Janoschka. 2014. La Ciudad Neoliberal. Gentrificación y exclusión en Santiago de Chile, Buenos Aires, Ciudad de México y Madrid. Hidalgo y Janoschka (ed.). la ed. Madrid: Instituto de Geografía, Pontificia Universidad Católica de Chile y Departamento de Ciencia Política y Relaciones Internacionales, Universidad Autónoma de Madrid. 
Instituto de Estadísticas y Regitro de la Industria de la Construcción-IERIC. 2005. "Situación actual y evolución reciente del sector de la construcción". Buenos Aires, Argentina.

Instituto de Estadísticas y Regitro de la Industria de la Construcción-IERIC. 2016. "Informe de coyuntura de la construcción:2015". Buenos Aires, Argentina. http://www.ieric.org.ar/publicaciones.asp.

Instituto Nacional de Estadísticas y Censos-INDEC. 2010. "Censo Nacional de Población, Hogares y Viviendas".

Jajamovich, Guillermo. 2017. "América Latina y las asimetrías de poder en abordajes sobre producción y circulación de políticas y teorías urbanas." Quid 16: Revista del Área de Estudios Urbanos 8 (7): 160-73.

Jajamovich, Guillermo. 2018. "Promocionando grandes proyectos urbanos: cuestiones (trans)locales en Puerto Madero (Buenos Aires), 1989-2017". Revista de Urbanismo 38 (38): 1.

LaVoz. 'Juez: A la ciudad no la definen las constructoras'". Diario La Voz del Interior, el 19 de noviembre de 2005.

http://archivo.lavoz.com.ar/NotaAnterior.asp?nota_id=372949\&high=Camara $\% 252$.

LaVoz. 2008. "La concertación con Edisur incluirá dos dispensarios", el 19 de septiembre de 2008. archivo.lavoz.com.ar/nota.asp?nota_id=241597.

LaVoz. 2014. "Mestre les pidió la renuncia a todos los funcionarios, menos a Alberto Giménez." La voz del interior, Politica, el 25 de abril de 2014. https://www.lavoz.com.ar/politica/mestre-les-pidio-la-renuncia-todos-losfuncionarios-menos-alberto-gimenez.

LaVoz. 2016. "Una multitud de oradores en la audiencia por el ex Batallón 141", el 14 de junio de 2016. https://www.lavoz.com.ar/ciudadanos/una-multitud-deoradores-en-la-audiencia-por-el-ex-batallon-141.

LaVoz. 2017. "Un batallón de beneficios que tardan en llegar'". Diario La Voz del Interior, ciudadanos, el 18 de marzo de 2017. https://www.lavoz.com.ar/ciudadanos/unbatallon-de-beneficios-que-tardan-en-llegar.

Levenzon, Fernanda. 2012. “La función social de la propiedad en términos de derechos humanos: implicaciones para la reforma del Código Civil". Revista Argentina de Teoría Jurídica Volumen 12.

Logan, John y Harvey Molotch. 2015. "La ciudad como máquina de crecimiento". En El mercado contra la ciudad: sobre globalización, gentrificación y politicas urbanas, editado por Traficante de Sueños, 157-210. Madrid, España.

López Morales, Ernesto, Ivo Gasic y Daniel Meza. 2012. “Urbanismo pro-empresarial en Chile: políticas y planificación de la producción residencial en altura en el pericentro del Gran Santiago". Revista INVI 27 (76): 75-114.

Maldonado, Mercedes, Felipe Pinilla, Francisco Rodríguez, y Natalia Valencia. 2006. Planes parciales, gestión asociada y mecanismos de distribución equitativa de cargas y beneficios en el sistema urbanistico colombiano. Lincoln Institute of Land Policy. 
Manzanal, Mabel. 1995. "Globalización y ajuste en la realidad regional argentina: reestructuración o difusión de la pobreza ?" Realidad económica 134: 67-82.

Maricato, Erminia, y Jsw Ferreira. 2002. “Operação urbana consorciada: diversificação urbanística participativa ou aprofundamento da desigualdade?" En Estatuto da Cidade e Reforma Urbana: novas perspectivas para as cidades brasileiras., OSÓRIO; L. M. (org.), 1-18. Porto Alegre: Sergio Antonio Fabris.

Mattos, Carlos De. 2007. "Globalización, negocios inmobiliarios y transformación urbana". Nueva Sociedad, núm. 212: 82-96.

Mattos, Carlos De. 2011. "De la planificación a la governance: implicancias para la gestión territorial y urbana". Revista Paranaense de Desenvolvimento, 9-23.

Municipalidad de Córdoba. Digesto municipal. Ordenanzas varias.

Peck, Jamie, Nik Theodore, y Neil Brenner. 2009. "Neoliberal Urbanism: Models, Moments, Mutations". SAIS Review 29 ( 1 ): 49-66.

Peck, Jamie, y Adam Tickell. 2014. "Neoliberalizing Space”. Antipode, núm. July 2002.

Pradilla Cobos, Emilio. 1997. "Regiones o territories, totalidad y fragmentos: Reflexiones criticas sobre el estado de la teoria regional y urbana". Eure 22 (68): 45-55.

Sandroni, Paulo. 201 1. “Experiencia reciente con la recuperación de plusvalías en São Paulo, Brasil".

Cambridge.

https://www.lincolninst.edu/es/publications/articles/experiencia-recientecon-la-recuperacion-plusvalias-en-sao-paulo-brasil.

Sautu, Ruth. 2005. Manual de metodología. Construcción del marco teórico, formulación de los objetivos y elección de la metodología. Buenos Aires: CLACSO.

Smolka, Martim O. 2014. "La Otorga Onerosa del Derecho de Construir en BrasilCEPACs y otros instrumentos". Quito. www.lincolninst.edu.

Terraza, Horacio, Bárbara Pons, Martin Soulier Faure, y Andrés Juan. 2015. Gestión urbana, asociaciones público-privadas y captación de plusvalias: El caso de la recuperación del frente costero del río Paraná en la Ciudad de Rosario, Argentina. Banco Interamericano de Desarrollo (BID).

Theodore, Nik, Jamie Peck, y Neil Brenner. 2009. “Urbanismo neoliberal: la ciudad y el imperio de los mercados". Temas Sociales SUR, núm. 66: 12.

Topalov, Christian. 1978. La urbanización capitalista. Algunos elementos para su análisis. México: Edicol.

Zen, Daniel. 2013. “Urbanistas municipales argumentaron contra mega country que impulsa Mestre'". Diario Alfil, el 14 de noviembre de 2013. http://www.diarioalfil.com.ar/2013/11/14/urbanistas-municipalesargumentaron-contra-mega-country-que-impulsa-mestre/. 
(C) Copyright: Natalí Peresini, 2021

(C) Copyright: Scripta Nova, 2021.

Ficha bibliográfica:

PERESINI, Natalí. La institucionalización de "convenios urbanísticos" en el marco del proceso de neoliberalización de la gestión urbana local. Scripta Nova. Revista Electrónica de Geografía y Ciencias Sociales. Barcelona: Universitat de Barcelona, vol. 25, Núm. 1 (2021), p. 141-167 [ISSN: 1138-9788]

DOI: $10.1344 / \operatorname{sn} 2021.25 .32238$ 